\title{
A Rare Case of Enterococcus gallinarum- Associated Peritonitis and Literature Review
}

\author{
Paul Nguyen ${ }^{1}$, Suman Khicher ${ }^{2}$, Heba Osman ${ }^{1}$, Neel Patel ${ }^{1}$ \\ 1. Internal Medicine, Wayne State University School of Medicine, Detroit, USA 2. Rheumatology, Wayne State \\ University School of Medicine, Detroit, USA
}

Corresponding author: Paul Nguyen, ha6860@wayne.edu

\begin{abstract}
Peritonitis is a well-known complication seen with peritoneal dialysis. Peritonitis is associated with increased mortality risk and is commonly caused by gram-positive and gram-negative bacteria, but it can also be the result of fungal or viral infections. Therefore, it is imperative to obtain a peritoneal fluid sample to send for cell count with differential, gram stain, and culture prior to starting empiric antibiotic therapy. We report a case of peritoneal dialysis-related peritonitis caused by Enterococcus gallinarum, for which there has only been one other reported case in the medical literature. Our patient was initially placed on vancomycin and cefepime but continued to deteriorate until peritoneal fluid cultures revealed E. gallinarum. Based on sensitivities, the patient was treated with daptomycin and cefazolin, which resolved her peritonitis.
\end{abstract}

Categories: Gastroenterology, Infectious Disease, Nephrology

Keywords: peritonitis, peritoneal dialysis, vancomycin resistant enterococcus (vre), vancomycin, daptomycin, multidrug resistant organism (mdro)

\section{Introduction}

Peritonitis is a well-known complication seen with peritoneal dialysis (PD). The bacteria most commonly seen are gram-positive and gram-negative organisms. Another gram-positive organism that is seen in peritonitis is the Enterococcus species. Enterococci are facultative anaerobes found in the normal human gut flora and can lead to infections from translocation and contact contamination. Vancomycin-resistant enterococci (VRE) have been described since the early 1980s and since then has posed therapeutic challenges for physicians. These challenges have warranted antibiotics combinations to achieve synergy for eradicating resistant Enterococcal infections, i.e., infectious endocarditis and peritonitis.

Review began 12/05/2020 Review ended 12/22/2020 Published 12/27/2020

\section{(c) Copyright 2020}

Nguyen et al. This is an open access article distributed under the terms of the Creative Commons Attribution License CC-BY 4.0., which permits unrestricted use, distribution, and reproduction in any medium, provided the original author and source are credited.

\section{Case Presentation}

An 85 -year-old female patient with a history of coronary artery disease, aortic valve replacement (AVR), type 2 diabetes mellitus, and end-stage renal disease (ESRD) on PD presented to the emergency department with difficulty breathing and altered mental status. Her son, the primary caregiver, shared that the patient was recently discharged from subacute rehab following a below-knee amputation (BKA) and had been having diarrhea. No further review of systems was obtainable due to her clinical status.

Upon arrival, her blood pressure was $113 / 48 \mathrm{mmHg}$, heart rate of 69 beats per minute, respiratory rate of 20 breaths per minute, oxygen saturation of $99 \%$ on $100 \%$ non-rebreather mask, the temperature of $36.6^{\circ} \mathrm{C}$. Physical exam revealed an elderly, frail female who was not oriented. She had bilateral coarse rhonchi on auscultation of her lungs with decreased breath sounds at the right lung base. The heart exam was normal. The abdomen was tender to palpation as facial grimacing was noted. A PD catheter was in place, and the site was clean. The patient did not follow commands, but the neurologic exam was non-focal.

Further workup revealed blood urea nitrogen (BUN) $27 \mathrm{mg} / \mathrm{dL}$, creatinine $3.8 \mathrm{mg} / \mathrm{dL}$ (at baseline), mild hypokalemia at $3.5 \mathrm{mMol} / \mathrm{L}$, leukocytosis at $13.5 / \mathrm{mm}^{3}$. A stat computed tomography of her head showed no acute intracranial process, and a chest X-ray revealed a right pleural effusion with possible right lower lobe opacities, which were unchanged from the previous studies (Figure 1). 


\section{Cureus}

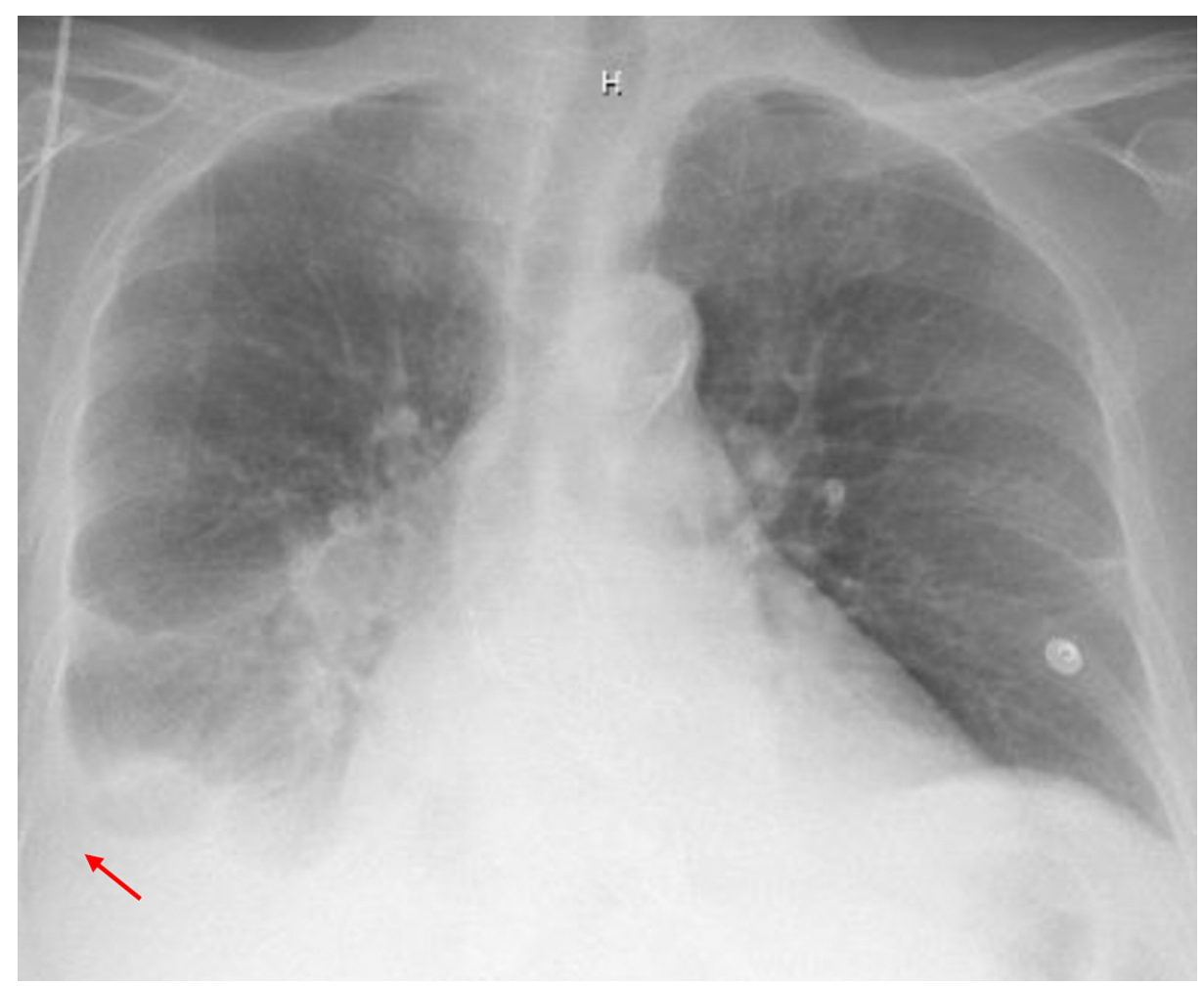

FIGURE 1: Chest X-ray depicting right-sided pleural effusion (red arrow)

She was then started on empiric antibiotics, including vancomycin, cefepime, and doxycycline, and admitted to the intensive care unit for severe sepsis. Infectious disease was consulted and recommended switching cefepime to ceftriaxone as the patient's mental status continued to deteriorate, in addition to sending peritoneal fluid for analysis and culture. While awaiting PD fluid cultures, her blood cultures grew Methicillin-resistant Staphylococcus aureus (MRSA), leading to concerns for infective endocarditis given her AVR history. The peritoneal fluid analysis revealed neutrophilic predominance with results as follows: 3,938 nucleated cells, $82 \%$ neutrophils, $9 \%$ lymphocytes, $8 \%$ monocytes, and $1 \%$ eosinophils. Although

receiving empiric antibiotic therapy, the patient's clinical condition continued to deteriorate. On the fifth hospital day, the patient's peritoneal fluid culture revealed Enterococcus gallinarum resistant to vancomycin. The patient was subsequently placed on IV daptomycin and cefazolin for synergy with improvement in her mental status within 48 hours. Repeat peritoneal fluid analysis showed decreased leukocytes and clearance of her E. gallinarum on repeated fluid cultures. The susceptibilities for E. gallinarum are listed in Table 1.

\begin{tabular}{|c|c|c|c|c|}
\hline & MIC & ET2SUSP & Interpretation & ET2 interpretation \\
\hline Antimicrobial & Rare Enterococcous gallinarum & Rare Enterococcous gallinarum & & \\
\hline Ampicillin & 1 & & $\mathrm{~S}$ & \\
\hline Daptomycin & & 4 & & $\mathrm{~S}$ \\
\hline Gent Syn Screen & $\leq 500$ & & $\mathrm{~s}$ & \\
\hline Linezolid & & 2 & & $S$ \\
\hline Streptomycin synergy & $\leq 1000$ & & $S$ & \\
\hline
\end{tabular}

\section{TABLE 1: Susceptibilities for Enterococcus gallinarum}

MIC - minimum inhibitory concentration; ET2SUSP - electrophoretic type 2 susceptibility; ET2 - electrophoretic type 2; S - susceptible; Gent Syn sentamycin synergy

A transthoracic echocardiogram was performed as the patient also had persistent MRSA bacteremia, which did not show any vegetations or mass. A transesophageal echocardiogram (TEE) subsequently revealed a 


\section{Cureus}

large globular deformation of the posterior mitral leaflet bulging into the left atrium, measuring $2.0 \times 1.9 \mathrm{~cm}$ in size that was concerning for mitral valve abscess (Figures 2-3). Unfortunately, due to the patient's

worsening clinical status and considering the overall prognosis, the patient was placed in hospice care and died several days later. An autopsy was not performed.

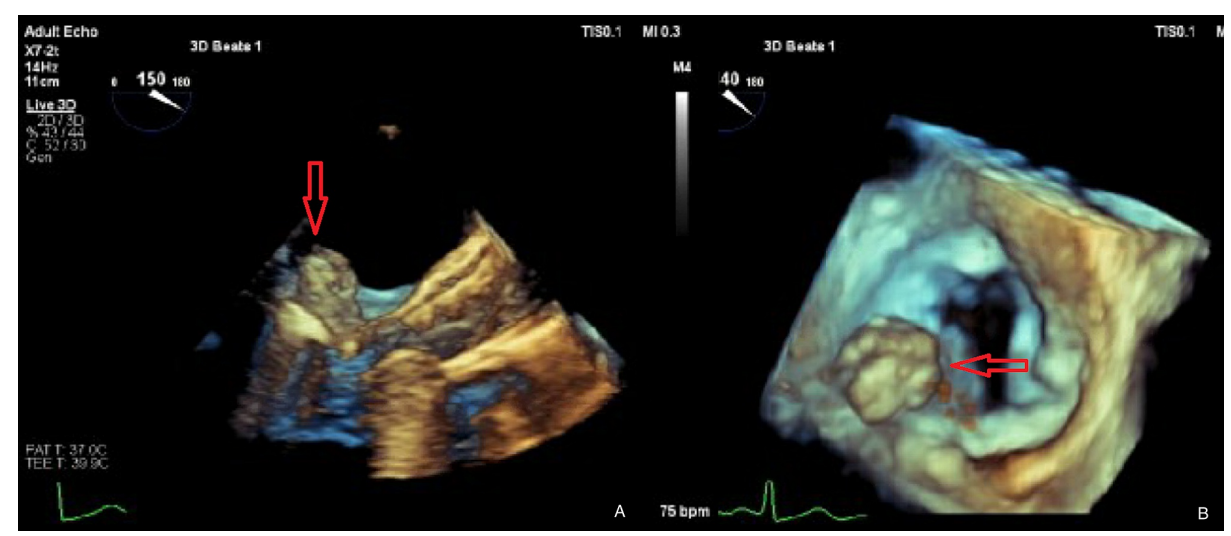

FIGURE 2: A: Midesophageal long-axis view showing large abscess of MV (red arrow). B: Atrial view of the MV showing abscess of posterior leaflet (red arrow).

MV - mitral valve

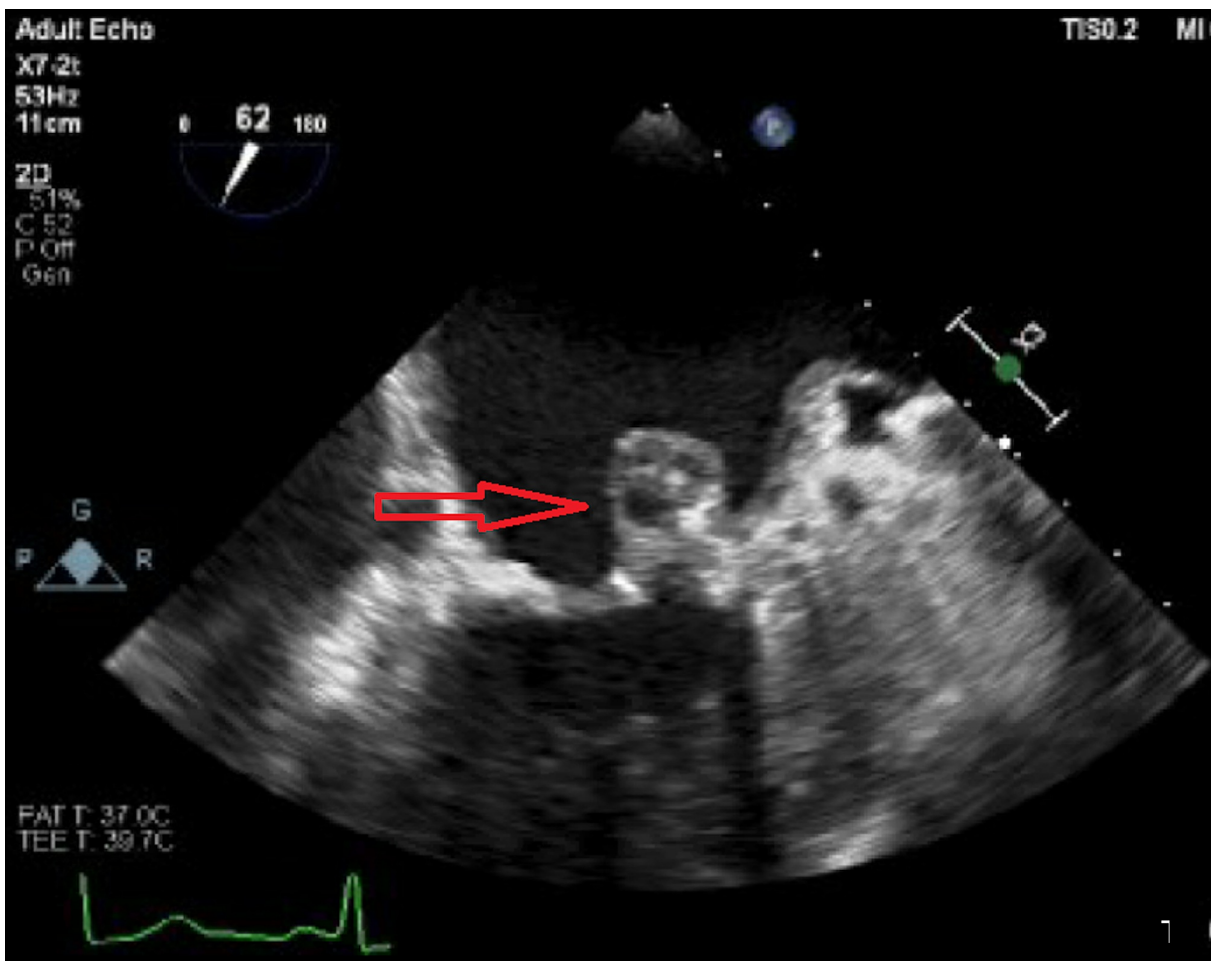

FIGURE 3: Two-chamber view showing abscess of mitral leaflet (red arrow)

\section{Discussion}

PD-related peritonitis is a widely known serious complication of PD as it is associated with increased mortality. It is also the leading cause of PD failure requiring transitioning to hemodialysis (HD) [1]. The most common gram-positive organisms seen are Staphylococcus aureus and other Staphylococcus spp. along with Escherichia coli and Klebsiella sp. for gram-negative organisms [2, 3]. Although VRE is not commonly seen in PD-related peritonitis, it alone increases the transition to permanent HD [4]. Enterococcus species are an essential component of the intestinal microbiota of healthy humans and animals [5, 6]. However, they can 
also cause opportunistic infections, which have been documented, leading to millions of annual infections [7]. There have been only a few reported cases of E. gallinarum peritonitis (Table 2); all have been associated with cirrhosis, i.e., part of spontaneous bacterial peritonitis, not PD-related peritonitis [8-12]. We present the second reported case in the medical literature of PD-related peritonitis caused by E. gallinarum [13]. It is not clear how our patient contracted E. gallinarum peritonitis, but it is likely due to fecal contamination. $E$. gallinarum has been reported as a rare cause of infective endocarditis (IE) in literature [14, 15]. Post-mortem evaluation of the valve tissue remains the gold standard for IE diagnosis as blood culture does not detect organisms in about one-third of the cases [16], so there can be a possibility of polymicrobial IE due to both MRSA and VRE in our patient.

\begin{tabular}{|c|c|c|c|c|c|}
\hline Reference & Age/Sex & Cause of cirrhosis & $\begin{array}{l}\text { Absolute neutrophil } \\
\text { count }\end{array}$ & Antibiotic used & Outcome \\
\hline Abidali et al. 2015 [8] & 60/Male & HCV & 944 cells/ $\square L$ & Ampicillin/Sulbactam & Survived \\
\hline Alvarez et al. 2002 [9] & 67/Female & HCV & Normal & Ampicillin & Survived \\
\hline $\begin{array}{l}\text { Narisco-Schiavon et al. } 2015 \\
\text { [10] }\end{array}$ & 63/Female & $\begin{array}{l}\text { Non-alcoholic } \\
\text { steatohepatitis }\end{array}$ & $2,610 / \mathrm{mm}^{3}$ & $\begin{array}{l}\text { Ampicillin \& } \\
\text { Gentamicin }\end{array}$ & Survived \\
\hline $\begin{array}{l}\text { Redondo-Cerezo et al. } 2002 \\
\text { [11] }\end{array}$ & 74/Female & HCV & $810 / \mathrm{mL}$ & Ampicillin & Expired \\
\hline Reuken et al. 2012 [12] & - & - & - & - & - \\
\hline \multicolumn{6}{|c|}{$\begin{array}{l}\text { TABLE 2: Reported cases of spontaneous bacterial peritonitis caused by Enterococcus } \\
\text { gallinarum }\end{array}$} \\
\hline HCV - hepatitis C virus & & & & & \\
\hline
\end{tabular}

E. gallinarum is one of the species in the Enterococcus family that is resistant to vancomycin. Vancomycin resistance is categorized as either low or high-level resistance. Vancomycin binds to the D-alanyl-D-alanine (D-Ala-D-Ala) moieties and prohibits cell wall synthesis. Enterococci develop resistance by substituting DAla-D-Ala for D-Alanine-D-Lactate (D-Ala-D-Lac) or D- Alanine-D-Serine (D-Ala-D-Ser) [17, 18]. The vanC operon transcribes a D-Serine and replaces the end terminus of D-Ala. This allows E. gallinarum to demonstrate low-level resistance (minimum inhibitory concentration [MIC], 4 to $32 \mu \mathrm{g} / \mathrm{mL}$ ) [19, 20]. Enterococci can develop resistance to our last resort antimicrobials used to treat glycopeptide and multidrug resistance (such as quinupristin-dalfopristin, linezolid, daptomycin, and tigecycline) [19]. Moreover, prior exposure to vancomycin adds a risk for drug resistance. Thus, once one obtains a culture for E. gallinarum, it is incumbent on the clinician to modify therapy as all E. gallinarum are resistant to vancomycin. One does not need to wait for sensitivities. However, if dealing with a concomitant MRSA infection with VRE providers can start daptomycin or linezolid.

\section{Conclusions}

In this case report, we report the second known case of PD-related peritonitis caused by E. gallinarum. Although, the most common causes of PD-related peritonitis are Staphylococcus aureus and other Staphylococcus spp. along with Escherichia coli and Klebsiella sp.; clinicians should be cognizant of other multidrug-resistant organisms in patients who do not respond to typical broad-spectrum antibiotics as antibiotic resistance continues to persist.

\section{Additional Information \\ Disclosures}

Human subjects: Consent was obtained by all participants in this study. Conflicts of interest: In compliance with the ICMJE uniform disclosure form, all authors declare the following: Payment/services info: All authors have declared that no financial support was received from any organization for the submitted work. Financial relationships: All authors have declared that they have no financial relationships at present or within the previous three years with any organizations that might have an interest in the submitted work. Other relationships: All authors have declared that there are no other relationships or activities that could appear to have influenced the submitted work.

\section{References}

1. Mujais S, Story K: Peritoneal dialysis in the US: evaluation of outcomes in contemporary cohorts . Kidney Int. 2006, 70:21-26. 10.1038/sj.ki.5001912 
2. Whitty R, Bargman JM, Kiss A, Dresser L, Lui P: Residual kidney function and peritoneal dialysis-associated peritonitis treatment outcomes. Clin J Am Soc Nephrol. 2017, 12:2016-2022. 10.2215/CJN.00630117

3. Jameson JL, Fauci AS, Kasper DL, Hauser SL, Longo DL, Loscalzo J: Dialysis. Harrison's Manual of Medicine. McGraw-Hill Education, New York; 2020. 20th edition:778-780.

4. Troidle L, Kliger AS, Gorban-Brennan N, Fikrig M, Golden M, Finkelstein FO: Nine episodes of CPDassociated peritonitis with vancomycin resistant enterococci. Kidney Int. 1996, 50:1368-1372. 10.1038/ki.1996.451

5. van Schaik W, Willems RJL: Genome-based insights into the evolution of enterococci . Clin Microbiol Infect. 2010, 16:527-532. 10.1111/j.1469-0691.2010.03201.x

6. Byappanahalli MN, Nevers MB, Korajkic A, Staley ZR, Harwood VJ: Enterococci in the environment. Microbiol Mol Biol Rev. 2012, 76:685-706. 10.1128/mmbr.00023-12

7. Moellering RC: Emergence of Enterococcus as a significant pathogen. Clin Infect Dis. 1992, 14:1173-1178. 10.1093/clinids/14.6.1173

8. Abidali H, Sheikh M, Abidali M, Abidali A, Farraji HS, Berry AC: Enterococcus gallinarum spontaneous bacterial peritonitis in an HCV cirrhotic. Case Reports Hepatol. 2015, 2015:1-3. 10.1155/2015/898235

9. Alvarez MA, Domènech E, Rosinach M, Lorenzo-Zúñiga V, Montoliu S, Planas R: Enterococcus gallinarum bacteriascites in a patient with active tuberculosis and HCV cirrhosis. Am J Gastroenterol. 2002, 97:26812682.

10. Narciso-Schiavon JL, Borgonovo A, Marques PC, et al.: Enterococcus casseliflavus and Enterococcus gallinarum as causative agents of spontaneous bacterial peritonitis. Ann Hepatol. 2015, 14:270-272. 10.1016/S1665-2681(19)30791-4

11. Redondo-Cerezo E, López FN, Tapia MJC, Blanco FS, García RM, Martin-Vivaldi R: Enterococcus gallinarum spontaneous bacterial peritonitis in an HCV cirrhotic woman. Am J Gastroenterol. 2002, 97:214.

12. Reuken PA, Pletz MW, Baier M, Pfister W, Stallmach A, Bruns T: Emergence of spontaneous bacterial peritonitis due to enterococci - risk factors and outcome in a 12-year retrospective study. Aliment Pharmacol Ther. 2012, 35:1199-1208.

13. Pérez Melón C, Ferreiro Álvarez B, Iglesias Lamas E, Camba Caride MJ, Borrajo Prol MP, Novoa Fernández E.: Enterococcus gallinarum and Chilaiditi syndrome in peritoneal dialysis. Nefrología. 2017, 37:213-214. 10.1016/j.nefro.2016.09.001

14. Dias MTA, de Almeida J, Santos A, Santos RM, Carvalho A: Enterococcus gallinarum causing native valve endocarditis. Eur J Case Reports Intern Med. 2019, 6: 10.12890/2019_001054

15. Angelos T, Nikolaos S, Nikolaos K, Nektarios P, Evdokia P: A rare case of tricuspid valve endocarditis caused by enterococcus gallinarum in a patient with recurrent urinary tract infection. Cardiovasc Hematol Disord Targets. 2018, 18:162-164. 10.2174/1871529x18666180302113428

16. Raja K, Antony M, Harikrishnan S: Infective endocarditis due to Streptococci and Enterococci: a 3-year retrospective study. Indian J Pathol Microbiol. 2018, 61:545-548. 10.4103/JJPM.IJPM_205_17

17. Arthur M, Quintiliani RJ: Regulation of VanA- and VanB-type glycopeptide resistance in enterococci . Antimicrob Agents Chemother. 2001, 45:375-381. 10.1128/aac.45.2.375-381.2001

18. Courvalin P: Vancomycin resistance in gram-positive cocci. Clin Infect Dis. 2006, 42:25-34. 10.1086/491711

19. Ahmed MO, Baptiste KE: Vancomycin-resistant enterococci: a review of antimicrobial resistance mechanisms and perspectives of human and animal health. Microb Drug Resist. 2018, 24:590-606. 10.1089/mdr.2017.0147

20. Cetinkaya Y, Falk P, Mayhall CG: Vancomycin-resistant enterococci. Clin Microbiol Rev. 2000, 13:686-707. 10.1128/cmr.13.4.686-707.2000 